\title{
Problems and Countermeasures in Landscape Design Education in China
}

\author{
Zhao Yin \\ Xi'an Siyuan University, Xi'an, Shaanxi, China, 710038
}

Keywords: landscape design; professional teaching; personnel training

\begin{abstract}
With the increasing demand for landscape design talents in the society, landscape design teaching has received increasing attention in colleges and universities. This paper points out that the landscape design of colleges and universities in China currently has the imperfect discipline training system and unbalanced supply and demand in the market. The root of the problem analysis lies in the aspects of inconsistent professional names, imperfect teaching systems, unreasonable curriculum, and disconnected training models from society. Through comparison with the setting and teaching situation of landscape subjects in Europe and the United States, this paper proposes that the landscape design in China should be improved and promoted from the aspects of professional construction, educational resource allocation, and training modes.
\end{abstract}

\section{Introduction}

In 1900, Olmsted set up a landscape architecture course and a four-year Bachelor of Science degree in Landscape Architecture at Harvard University, establishing its position as a modern discipline. China's landscape design discipline was introduced in the 1980s. After several years of development, there have been hundreds of institutions in China that have landscape design or related majors.

\section{Two Major Problems Faced by Domestic Landscape Design}

\subsection{The imperfect training system of landscape design}

The modern landscape major is mainly based on the different majors of different colleges and universities. It mainly includes architecture, urban planning, municipal engineering of architectural colleges, environmental arts of art colleges, and gardens of agricultural and forestry schools. The relevant majors of these colleges and universities are also composed of different disciplines. They are roughly divided into: architecture, agriculture, forestry, arts, and tourism. The curriculum content and training models of most other colleges and universities are mainly inherited from past horticultural and other disciplines, and in the international modern sense. There is still a certain gap between landscape design disciplines [1]. Landscape design diagram as shown below.

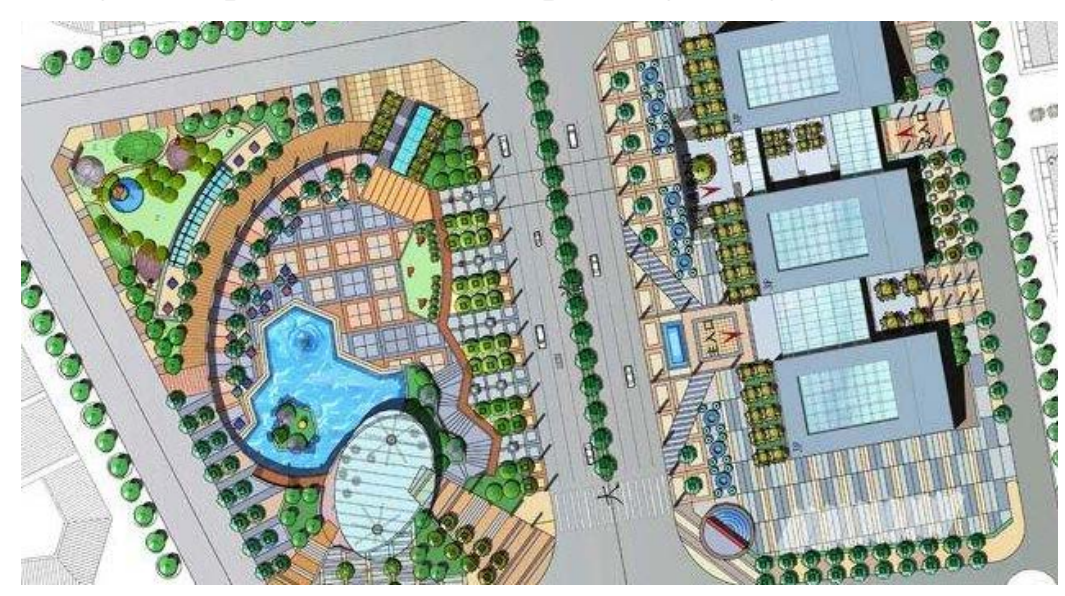

Fig.1 Landscape Design Sketch 


\subsection{Contradiction between talent supply and demand}

With the rapid development of landscape design disciplines, the landscape design industry has also ushered in the peak of vigorous development. With the rapid progress of urbanization in China, the ever-changing urban construction and the booming development of the real estate market, the business volume of the landscape industry is increasing. At the same time, the demand for landscape design talent in the industry and society has also increased. According to the data of the Building Talents Network, the demand for garden and landscape designers grows very fast, with a year-on-year increase of 78\% in the whole country in 2009 and 103\% in Zhejiang. The increasing demand for employment has made the landscape majors of various universities quickly become hot professions. Over the past five years, the number of undergraduate colleges with landscape majors has soared from the original 20 to more than 150. However, due to the incompleteness of the training system for landscape design majors in universities and the great differences in training objectives and orientation, there are a large number of landscape graduates who cannot truly ease the needs of employers. Many companies do not recruit suitable employees, and the contradiction between talent supply and demand is still outstanding.

\section{Cause Analysis of Two Major Issues in Landscape Design}

\subsection{The non-uniform professional names}

At present, there is no unified name for a unique landscape design profession in China. In the 1950s, the courses of the gardening profession initiated by Liang Sicheng and Wu Liangchun at Tsinghua University combine the characteristics of biology and engineering disciplines. Subsequently, the name of the domestic landscape professional experienced the "change of the garden - the greening of the city and the residential area - garden - landscape - landscape". In China, colleges and universities that specialize in landscape design are not only different in professional titles, but also in different disciplines. No matter if it is a separate setting of a college of agriculture or forestry or a college of science and engineering, it may be lost. The interdisciplinary cross-cutting and conflicts have led to the bias of domestic landscape education, and it has not been possible to make the landscape profession move towards complete unification in the short term [2].

\subsection{Lack of characteristic training mode}

In the training mode, domestic universities do not specifically set up the landscape professional training system, but follow the teaching methods of general science and engineering disciplines. In terms of curriculum setting, many other disciplines are used as references, and the teaching models of traditional disciplines such as gardens, gardening, architecture, and planning are used or referenced. There is no adaptation to landscape architecture. This emerging discipline is characterized by strong practicality, broad design knowledge, and quick knowledge update. . In addition, the proportion of public courses is too large, overemphasizing the unity of public courses, and ignoring the flexibility and diversity of professional courses is not conducive to the development of student professional learning [3].

\subsection{Lack of support of hardware facilities}

The education sector has so far had no criteria for the evaluation of landscape professionalism. The professional curriculum and teacher resources are all determined by the school itself. With the increase in the demand for landscape talent, some colleges and universities also set up this major regardless of whether they have the appropriate conditions. However, the landscape design is a practical, comprehensive professional, in addition to the need for a corresponding teaching site, but also requires supporting experimental training facilities, display and exchange facilities, and venue training space. However, at present, there are few complete hardwares in domestic universities, and some universities do not even have basic experimental and training facilities. The equipment used in teaching and training is old and more often used in ordinary classrooms. The imperfection of hardware has caused teachers to teach a single way, aging, and can not guarantee the quality of 
teaching. The calculation formula of the hardware supporting index is as follows.

$$
\xi_{i j}=\frac{\min _{i=1}^{m}\left\{\min _{j=1}^{n}\left(\left|z_{i j}-z_{0 j}\right|\right)\right\}+\eta \cdot \max _{i=1}^{m}\left\{\max _{j=1}^{n}\left(\left|z_{i j}-z_{0 j}\right|\right)\right\}}{\left|z_{i j}-z_{0 j}\right|+\eta \cdot \max _{i=1}^{m}\left\{\max _{j=1}^{n}\left(\left|z_{i j}-z_{0 j}\right|\right)\right\}}
$$

\section{Optimization of Development of Landscape Design}

\subsection{Find out the characteristics of landscape design teaching}

Combing the professional training system, according to the characteristics of the landscape professional to develop a professional teaching program suitable for the subject and scientific and rational curriculum. The landscape design profession needs the teaching system of art, sociology and ecology as a trinity and multi-disciplines. All domestic universities and colleges shall, based on the advantages of sharing resources within the school, make a combination of the characteristics of the school's curriculum design for the landscape design professional training model. In the United States, visits and visits have been a major component of landscape design education [4].

\subsection{Configurate hardware and equipment required}

Landscape design discipline teaching should be equipped with comprehensive facilities and equipment. Software and hardware equipment should be equipped with: site survey equipment, such as total station, digital camera, GPS handheld locator, CIS geographic system, etc.; input devices, such as high-performance graphics computer, hand-painted digital tablet, A3 scanner, engineering scan Instruments; output devices such as large format printers, color printers, engraving machines, copiers, etc.; related software, such as AUTOCAD, photoshop, coredraw, sketchup, etc.; supporting equipment, such as graphics workbenches, digital booths, projectors, 3D simulation demonstration System and so on. In terms of teaching venues, there is a series of supporting teaching venues, such as exhibition halls for exhibition works, project training venues, and engineering construction processing workshops. Cad design is as follows.

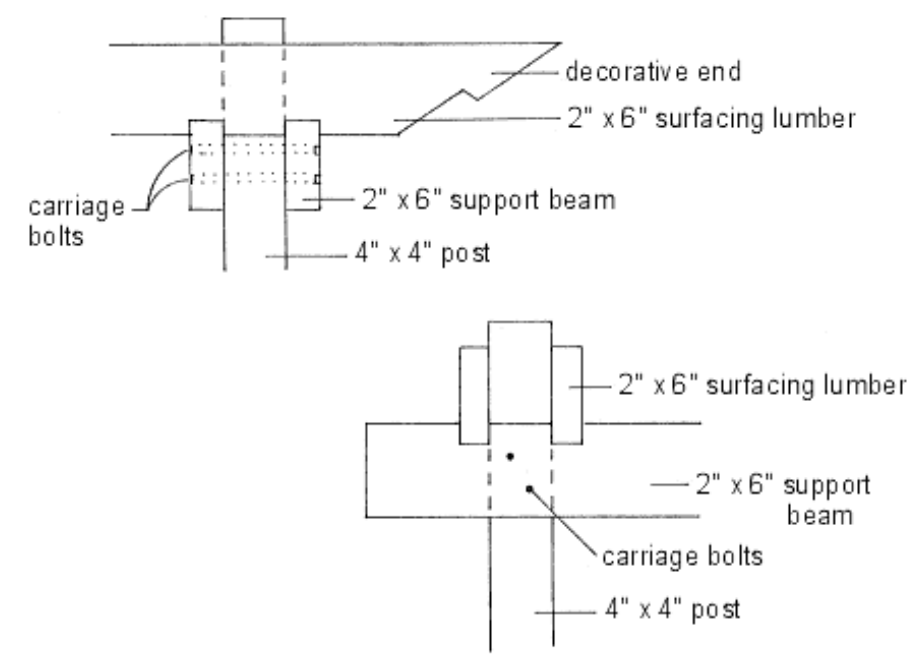

Fig.2 CAD Design

\subsection{Provide professional teacher development and exchange mechanism}

On the one hand, it provides professional teachers with a platform and space for integration with the industry. For example, faculty members of the Department of Landscape Architecture at the University of Sheffield in the UK have extensive research experience to study the content, teaching and quality of instructional teaching. Most teachers also carry out various landscape practices in their research fields. On the other hand, experts and scholars at home and abroad are regularly invited to the University for lectures and exchanges. For example, after establishing a landscape 
design major in the department of horticulture at the University of Wisconsin, the subject education was mainly conducted by inviting famous designers such as Jensen, Lloyd, Wright to give lectures.

\section{Summary}

As a discipline related to the human environment, the landscape design profession is increasingly valued as the social needs increase. In China's landscape design professional education, despite years of exploration and accumulation, there have been certain scales and achievements, but there are also problems such as inconsistent professional names and incomplete training systems. The landscape design profession has a strong practicality and comprehensiveness. The training mode should be based on its own nature, through the unification of professional titles, the development of a scientific and rational teaching plan, emphasizing the integration and aggregation of disciplines, and strengthening the links and cooperation with the society and industry. The training mode provides support and encouragement for the development of teachers' personal professional space. It aims to cultivate a diverse knowledge structure, high-quality, and comprehensive landscape design professionals with practical skills, and to meet the current society's landscape design. Talent demand standards and the development of landscape design disciplines make greater contributions.

\section{References}

[1] Jun Cui, Cuiling Jiang. Building highway landscapes: innovative directions for urban wastewater treatment in the face of new challenges in China[J]. Procedia Engineering,2011,21.

[2] Xiaolong Gan, Jian Zuo, Ruidong Chang, Dezhi Li, George Zillante. Exploring the determinants of migrant workers' housing tenure choice towards public rental housing: A case study in Chongqing, China[J]. Habitat International,2016,58.

[3] Allan Walker, Haiyan Qian. Review of research on school principal leadership in mainland China, 1998-2013[J]. Journal of Educational Administration,2015,53(4).

[4] Venka Simovska, Ros Kane. Sexuality education in different contexts: limitations and possibilities[J]. Health Education,2015,115(1). 